\title{
Research Paper: Percentage of Consonants Correct for 3-5 Years Old Kurdish-Speaking Children With Middle Kurmanji-Mukryani Dialect
}

\author{
1. Department of Speech Therapy, University of Social Welfare and Rehabilitation Sciences, Tehran, Iran. \\ 2. Institute of Linguistics, Institute for Humanities and Cultural Studies, Tehran, Iran. \\ 3. Department of General Linguistics, Farhangian University, Sanandaj, Iran. \\ 4. Department of Biostatistics, University of Social Welfare and Rehabilitation Sciences, Tehran, Iran.
}

Shahla Fatemi Syadar ${ }^{1}$, Talieh Zarifian ${ }^{1 *}$, , Yahya Modarresi ${ }^{2}$, Muhamad Sediq Zahedi ${ }^{3}$, Mona Ebrahimipur ${ }^{1}$, Akbar Biglarian $^{4}$

Article info:

Received: 26 Aug 2017

Accepted: 28 Jan 2018

Keywords:

Percentage of consonant correct, Test, Articulation, Child, Kurdish language
Citration: Fatemi Syadar Sh, Zarifian T, Modarresi Y, Sediq Zahedi M, Ebrahimipur M, Biglarian A. Percentage of Consonants Correct for 3-5 Years Old Kurdish-Speaking Children With Middle Kurmanji-Mukryani Dialect. Iranian Rehabilitation Journal. 2018; 16(2):155-162. http://dx.doi.org/10.32598/irj.16.2.155

http://dx.doi.org/10.32598/irj.16.2.155 


\section{Introduction}

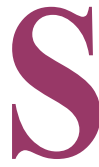

peech Sound Disorder (SSD) is a speech disorder in which some speech sounds (called phonemes) in a child's (or, sometimes, an adult's) language are either not produced, not produced correctly, or are not used correctly. SSD in children is one of the most common forms of communication disorders reported by Speech-Language Pathologists (SLPs) [1, 2]. The prevalence of SSD varies among preschool children (between $10 \%$ and 15\%) [3] and school-age children (6\%) [4]. Speech and language development is approximately related to all aspects of social and educational development [5]. Children with mild speech disorders may be socially isolated, and children with severe disorders may have more difficulties in terms of health, education and vocation. Many studies cited that children with speech and language disorders are at the risk of having learning and educational problems [6-9].

Shriberg et al. (1997) have introduced a speech intelligibility scale and Percentage of Consonant Correct (PCC) scale as an index of speech development and the severity of the disorder. Generally, calculating of speech intelligibility index is according to the percentage of intelligible words in connected speech that is relatively simple and subjective criteria and will not be counted as the number of sounds error [10]. But, Shriberg and Kwiatkowski (1982) have evolved PCC as a standard criterion to evaluate the performance of phonological system in children. They recommended calculating of PCC in speech sample in order to judge about phonological abilities and the degree of disorders in children [11].

Percentage of Consonant Correct (PCC) and Percentage of Vowel Correct (PVC) are two quantitative measures, which are important in confirmation and documentation of children's phonological development or/and their severity of difficulty [12]. For the first time, Shriberg and Kwiatkowski (1982) introduced PCC as the Articulation Competence Index (ACI) that was calculated by using connected speech sample data from children with phonological disorder. They calculated PCC via division of the number of correct consonants by the total number of consonants in the sample [13].

Many studies reported information about the PCC in many languages of the world and their different dialects, including English and its different dialects that are spoken in different regions of the world such as: American English, African English, Canadian, Australian and a large number of various dialects of the this language
[14]. Also, are obtained in different languages around the world, including Arabic, Turkish, French, Chinese, Spanish, Persian, Cantonese, Malay, Germany, Swahili [14-24].The results of these studies suggest when children reach the age of 2 years; approximately they pronounce $70 \%$ of consonants correctly. For example, Watson and Scukanec (1997) obtained PCC data for 12 children from United States, longitudinally. Mean percentage of PCC for children aged 2 years was $69.2 \%$ and increased $82.2 \%$ up to age 3 years. PCC increases by growing of children. Also, Dodd et al. (2003) found that children ages 5 ; 6 to 6 ; 6 years produced $95.9 \%$ consonants correctly [13]. Pollock (2002) reported PCC of American-English speaking children aged between 1.6 to 6.11 years. The results of study showed consonant accuracy of $92 \%$ for children aged between 3 to 3.5 years and consonant accuracy of $97 \%$ for children aged between 6 to 6.5 years [13]. Zarifian et al. (2014) studied PCC in Persian speaking children aged between 3 to 6 years. The results showed mean percentage of correct consonants $87.98 \%$ in children aged between 3 to 3.5 years and $94.57 \%$ in children aged between 5.5 to 6 years [19]. All these studies show that PCC increases with age and older children have better PCC score. So, respectively, children of ages 3 and 6 years show minimum and maximum PCC [25].

There are some methods for calculating PCC. Nowadays, single word speech sample is used as more practical and more time-efficient but Shriberg and Kwiatkowski (1982) calculated it by using connected speech (at least 200 words) [11]. However, Dodd et al. (2003) used the single word from Diagnostic Evaluation of Articulation and Phonology (DEAP) test [26]. Zarifian et al. (2014) used single word speech sample to present of PCC Scale and introduced it as a reliable and valid instrument for evaluating articulation competence index of Persian speaking children in the clinical settings and research projects [25].

Kurdish language is an Indo-European language belonging to the Western Iranian languages group of the Indo-Iranian branch of the family [27-29]. Kurdish language is spoken approximately by forty million people living mainly in Turkey, Iran, Iraq, and Syria [30]. This language is divided into four main dialects, namely, Northern Kurmanji, Middle Kurmanji (Sorani), Southern Kurmanji, and Gorani (Hawrami). The Middle Kurmanji (Sorani) itself, includes some dialects. Middle Kurmanji-Mukryani can be named as one of the comment dialects of Middle Kurmanji in Iran $[27,28,31]$. 
Kurdish language contains 30 consonants and 8 vowels [32]. The consonants of Kurdish language with Middle Kurmanji-Mukryani dialect include nine stops ( $\mathrm{p}, \mathrm{b}, \mathrm{t}$, $\mathrm{d}, \mathrm{k}, \mathrm{g}, \mathrm{q}, \mathrm{P}, \mathrm{S}$ ), ten fricatives ( $\mathrm{f}, \mathrm{v}, \mathrm{s}, \mathrm{z}, \mathrm{\int}, \mathrm{3}, \mathrm{x}, \mathrm{\gamma}$, $\mathrm{h}, \mathrm{h})$, two affricatives ( $\mathrm{g}, \mathrm{d})$ ), three nasals ( $\mathrm{m}, \mathrm{n}, \mathrm{y})$, two laterals $(1,1)$, one flap (r), one trill (r), and two glides (w, j) $[30,32-34]$.

The language phonemes in various dialects of Kurdish language, such as "Hawrami and Sorani" are almost the same, though with subtle differences. As a case in point, the frequency of consonant $/ \mathrm{v} /$ and $/ \mathrm{y} /$ in different dialects of Kurdish Language is different in a way that it has high frequency in Northern Kurmanji but low frequency in Middle Kurmanji. This difference does not lead to phonological contrast and producing the minimal pairs in Middle Kurmanji-Mukryani dialect [33]. Syllable structure in the Kurdish language is $(\mathrm{C}) \mathrm{CV}(\mathrm{C})(\mathrm{C})(\mathrm{C})$ that can be attributed to all the different dialects and accents of Kurdish language [31, 34-36]. Kurdish language has consonant clusters at the beginning of syllables, but their number is limited [31, 33-36].

As there is no articulation competence index ACI in the Kurdish language, the aim of this study was to determine the percentage of consonant correct in the intended age groups and study the effect of manner and place of articulation on consonants accuracy and finally, compare this scale in girls and boys.

\section{Methods}

\section{Participants}

In this descriptoanalytical and cross-sectional study the participants were 120 (60 males and 60 females) Kurdish Speaking children aged between 3-5 years old, from Bukan City, Western Azerbaijan, Iran. Children were recruited randomly from health centers and nursery schools at mid-July to late August in 2015. The participants were divided into four age groups based on 6-month intervals, as follows: 3-3.5, 3.6-4, 4-4.5, 4.6-5. Each group was divided into two subgroups with an equal distribution of 15 males and 15 females. Participants were recruited based on the examination records and examiner's observations and the information provided by parents' and nursery school teachers' anecdotes in the research based demographic and health questionnaire. Children meeting the following conditions were selected for the study: a) Age between three to five years (36 months to total 60 months); b) Monolingual Kurdish speaking children with parents whose first language was Kurdish; c) Having healthy oro-facial structure and function (informal assessment by the examiner); d) Normal psychomotor development (research based questionnaire); and, e) Parent's completion of the consent form for the child's participation in the study. Children who met the following criteria were excluded from the study: a) Having history of the delay in the child's language development (informal assessment by the examiner and the research made questionnaire); b) Having vision, hearing, mental, emotional, and psychological deficiencies, or history of head injuries or obvious neurological disorders, such as seizures, epilepsy, and autism spectrum disorders (research made questionnaire); and, c) Having a history of speech therapy $[6,17,37]$.

The ethical considerations were approved by the Ethics Committee of the University of Social Welfare and Rehabilitation Sciences.

\section{Procedure and materials}

Accuracy of Kurdish language consonants and the extraction of words containing intended consonant was obtained via Kurdish Phonetic Test (KPT). Formerly, psychometric features of test had verified 120 children aged between 3 to 5 years. KPT contains 82 pictures for 29 consonants in the Middle-Kurmanji dialect of Kurdish language in three word positions (initial, medial, and

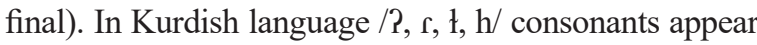
just in one or two positions; thus, the number of pictures was 82 . The target words varied in length from one to four syllables. All the words were nouns. Generally, all words were picturable, familiar and culturally appropriate for young Kurdish children.

The examiner, the first author, who is a Kurdish speaking speech and language pathologist with Middle Kurmanji-Mukryani Dialect, evaluated all children, individually, in a quiet room with the adequate light and a comfortable seat for children. When children could not name the picture spontaneously, the examiner helped them by using conveyer sentences, practical questions or direct and delay imitation. Both voice recording and simultaneous transcription by the examiner were used to document the children's vocalizations. Each correct consonant production was given a score of 1 . The implementation of the test lasted for about 15 to 20 minutes.

Three aspects of accuracy were studied and compared in each age group: (1) Total percentage of accuracy, (2) Accuracy based on the manner of articulation (stop, affricative, fricative, nasal, glide, trill, lateral, flap), (3) accuracy based on the sound position in the word (initial, medial and final). 
The materials used in this study contained a demographic questionnaire (children's personal information), consent forms, researcher made phonetic test, phonetic test answer sheet, a voice recorder (model: Samsung SM-G360), a laptop (DELL model), and the SPSS statistical software version 19. The overall percentage of accuracy was calculated by PCC that was obtained via the division of the number of correct consonants by the total number of consonants in the target sample.

$P C C=\frac{\text { The number of correct consonants }}{\text { The total number of consonants }} \times 100$

Variables of this study were age, sex and percentage of consonant. The Shapiro-Wilk test was used in order to verify compliance data distribution with normal distribution. All statistical analyzes was done in SPSS software version 19 and was considered at $\alpha=0.05$ significance level.

\section{Validity and reliability of Kurdish Phonetic test}

Content validity of the test calculated by the Lawshe's method, according to the opinions of Kurdish speech and language therapists and linguists experts, was between 80 $100 \%$ [38]. The test-retest reliability, with one-week interval, and intra-rater reliability, determined by the test, were also calculated. Both reliability measures were conducted randomly on $26.6 \%$ of the participants (four persons from each gender and age group, a total of 32 participants). The results indicated no significant difference in pronunciation of sounds between the first and second week. Content stability, and inter-rater reliability were investigated in $10 \%$ of participants (12 children with mean age of 44 months) by two independent examiners ( $\mathrm{P}>0.05)$. The mean percentage of agreement between the scores given by the independent assessors was 91.33 and varied between 0.83 to $100 \%$ [39]

\section{Results}

The present study was conducted on 120 children, aged 3 to 5 years with a mean age of 41 months and standard deviation of 0.5 , who entered the study according to an inclusion and exclusion criteria. Table 1 presents the demographic characteristics of the data.

\section{Percentage of correct consonant}

The mean percentage and standard deviation of consonant accuracy according to the gender and age group for all 30 children in each group are presented in the Table 2. It was derived that the percentage of accuracy increased with age and respectively from lower age group to higher age group. Comparison of age groups separately together showed the same result. Generally, older children had more accuracy of the consonant $\left(\mathrm{X}^{2}=29.97 ; \mathrm{P}<0.001\right)$ (Table 3). The results indicated better performance of girls than boys, at higher age groups, but the difference was not significant $(\mathrm{Z}=-0.71 ; \mathrm{P}=0.47)$ (Table 4$)$.

\section{Percentage of consonants correct based on manner of articulation}

The percentage of correct consonant production, based on the manner of articulation, indicated that children have

Table 1. Demographic characteristics of participants according to age

\begin{tabular}{cccc}
\hline Age Group (in Month) & Number (\%) & Mean (in Month) & SD* \\
\hline $36-41$ & $30(25)$ & 38 & 0.1 \\
$42-47$ & $30(25)$ & 44 & 0.1 \\
$48-53$ & $30(25)$ & 50 & 0.1 \\
\hline $54-60$ & $30(25)$ & 56 & 0.1 \\
\hline SD: Standard Deviation & & !ranian Rehabilitation Journal
\end{tabular}

Table 2. Mean percentage and standard deviation of consonant accuracy according to gender and age group

\begin{tabular}{|c|c|c|c|}
\hline \multirow{2}{*}{ Age Group } & \multicolumn{2}{|c|}{ Gender } & \multirow{2}{*}{ Total } \\
\hline & Female & Male & \\
\hline $36-41$ & $83.49(8.92)$ & $83.90(9.73)$ & 83.69(9.17) \\
\hline $42-47$ & $86.50(8.61)$ & $88.45(6.13)$ & $87.47(7.41)$ \\
\hline $48-53$ & $93.57(1.62)$ & $91.13(4.05)$ & $92.35(3.28)$ \\
\hline $54-60$ & $95.93(2.14)$ & $91.86(4.95)$ & $93.90(4.28)$ \\
\hline
\end{tabular}

The corresponding standard deviations are shown in parentheses.

Iranian Rehabilitation \ournal 
Table 3. Kruskal Wallis test to compare the mean scores of consonant accuracy according to age group

\begin{tabular}{ccccc}
\hline Age Group & Mean & Chi-Squared & df & Significance Level \\
\hline $36-41$ & 32.45 & & \\
$42-47$ & 60.82 & 29.978 & 3 & 0.001 \\
$48-53$ & 71.18 & & \\
$54-60$ & 77.55 & & \\
\hline
\end{tabular}

Ilranian Rehabilitation Journal

Table 4. Mann Whitney test to compare the mean scores of consonant accuracy according to gender

\begin{tabular}{ccccc}
\hline Sex & Mean (SD) & U-Mann Whitney & Z & Significance Level \\
\hline Male & $88.84(7.14)$ & & & \\
Female & $89.87(8.01)$ & 29.978 & -0.07 & $\mathrm{P}=0.47$ \\
\hline
\end{tabular}

Iranian Rehabilitation Journal

more accuracy in pronunciation of nasal, glide, lateral, stop, flap, fricative, affricative and trill consonants, respectively. There was no significant difference between boys and girls $(\mathrm{P}>0.05)$. Generally, girls operated better than boys. Table 5, displays the mean and standard deviation.

\section{Percentage of consonants correct according to} sound position in word

The mean and standard deviation of the percentage of correct consonants, according to the position, indicated that generally consonant accuracy in the initial position is better than the medial position and the medial position is better than the final position. The mean suggested better performance of girls than boys, but, there was no significant difference between boys and girls $(\mathrm{P}>0.05)$. Figure 1, displays the reported percentage of consonant correct, according to the position.

\section{Discussion}

The present research studies the percentage of consonant correct in Kurdish speaking children, aged 3 to 5 years, with Middle Kurmanji-Mukryani Dialect. The aim of this study, is determining of the percentage of correct consonants in the intended age groups, evaluating the effect of manner and place of articulation on con-

Table 5. Mean percentage and standard deviation of consonant accuracy based on manner of articulation

\begin{tabular}{|c|c|c|c|}
\hline \multirow{2}{*}{ Manner of Articulation } & \multicolumn{2}{|c|}{ Gender } & \multirow{2}{*}{ Total } \\
\hline & Female & Male & \\
\hline Nasal & $100(0)$ & $100(0)$ & $100(0)$ \\
\hline Glide & $94.16(12.58)$ & $95.27(8.17)$ & $94.72(10.58)$ \\
\hline Lateral & $95.66(13.32)$ & $92.66(16.03)$ & $94.16(14.75)$ \\
\hline Stop & $93.80(4.96)$ & $93.33(5.49)$ & $93.56(5.21)$ \\
\hline Flap & $91.66(27.87)$ & $90.83(28.36)$ & $91.25(28.00)$ \\
\hline Fricative & $85.63(10.20)$ & $84.54(9.12)$ & $85.08(9.65)$ \\
\hline Affricative & $80.83(26.18)$ & $75.55(29.98)$ & $78.19(28.15)$ \\
\hline Trill & $76.66(40.84)$ & $76.66(40.84)$ & $76.66(40.84)$ \\
\hline
\end{tabular}

The corresponding standard deviations are shown in parentheses.

Iranian Rehabilitation Journal 


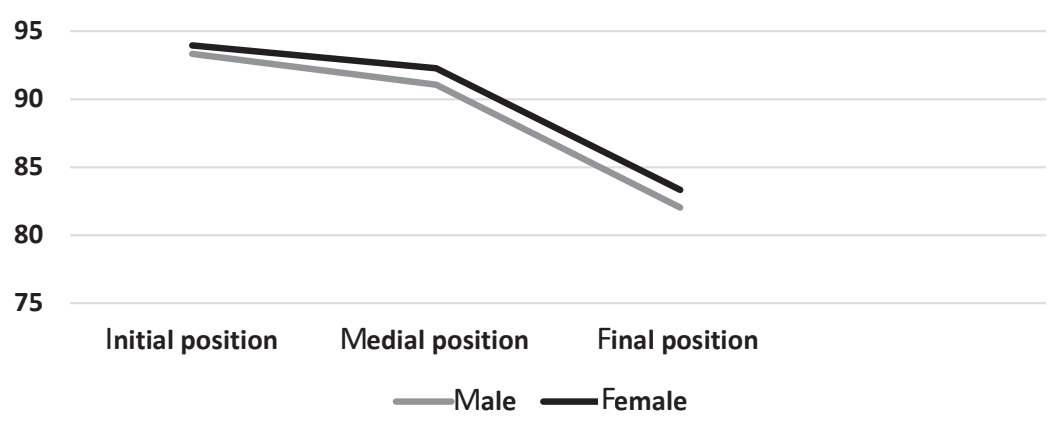

Iranian Rehabilitation Journal

Figure 1. Comparison of mean percentage of consonant accuracy in total, for girls and boys, based on the position of consonant in the word

sonants accuracy and finally checking this scale in girls and boys and comparing them together.

The results of the study showed that PCC in Kurdish speaking children with Middle Kurmanji-Mukryani Dialect consisted with PCC in Persian and English speaking children, with little difference. The mean and standard deviations of PCC in Persian speaking children were 93.13 and 8.53 respectively; of course it was studied in a more comprehensive sample and children aged 3 to 6 years [25]. Also, according to Dodd et al. (2003) this mean and standard deviation was 90.81 and 10.14 [26].

The present study results are consistent with a number of other studies, especially about effect of gender on Kurdish language PCC. Yet, there has not been an agreement about the significance of the effect of gender on children's speech acquisition. However, there are studies that reported girls demonstrated better speech production than boys. Several studies reported a significance level in special age groups. For example, Wellman et al. (1931) indicated that consonant accuracy in younger age group children ( 3 and 4 years) is more significant than in children of 5 and 6 years $[13$, 40]. On the other hand, Poole (1934) claimed that gender differences was revealed after 5.6 years, in which girls showed faster growth and complete speech sound acquisition one year earlier than boys [13, 40, 41]. In another study, Smit et al. (1990) found the effect of gender differences between children aged 4-4.6 years and 6-years. Dodd et al. (2003) found that girls in the older age group showed a higher phonological accuracy score than boys [26]. Amayreh and Dyson found no significant difference between the performance of girls and boys, but generally reported a better performance of girls as compared with boys [15]. Zarifian et al. (2014) found no significant difference between percent consonant accuracy of girls and boys [25]. Phoon et al. (2014) reported the effect of gender on Malay speaking children and concluded that female children have more accuracy than male children [17].

This finding - higher speech skills of girls than boys - is consistent with clinical studies that had reported a higher number of boys being referred for speech and language therapy [26]. Also, the data from this study is consistent to studies reporting the effect of gender on speech disorder. Shriberg, Tomblin and McSweeny (1999) reported a high prevalence of speech delay in 6 year- old boys $(4.5 \%)$, in comparison to girls $(3.1 \%)$ [42].

The finding of consonant position in the word in this study was consistent to English studies like Wellman (1931) and Templin (1957) and Malay study [13, 17, 40]. This study revealed that consonant accuracy in the initial position was better than in the medial and final positions but, Arabic speaking children produce medial position better than the two other positions [15]. Actually, less accuracy of final consonants may be because of phonetic features of Kurdish language, for example, simplification process or final devoicing or final deletion consonant. So, these findings approve the importance of sound position in the word or in the syllable.

High percentage of accuracy in nasals, glides and stops agree with a large number of studies in English, Arabic, Germany, Malay, Persian [12, 15, 17, 19, 20, 26]. According to these studies, lower accuracy of affricatives than other manners of articulation such as nasals and stops is consistent with the finding of the present study. On the other hand, Phoon et al. (2014) found that Malay speaking children have more accuracy of affricative consonants than stops and nasals. Also, accuracy of glides in Malay children indicated minimal accuracy (76.09), in contrast to Kurdish children where it was maximal accuracy $(94.72 \%)$, but in case of fricatives it has reported a similar percentage [17]. The results of this study showed that PCC is related with age and it is 
an indicative of gradual development of Kurdish language phonological system. It seems consonants development occurs after 5 years, however this study does not have any evidence about this claim. This is not surprising, older children have a more complete phoneme inventory than younger age groups children. Actually, children pronounced most of their tongue mother consonants correctly at 2-3 years only.

As regards the study conducted on a small sample of Kurdish speaking children and small region of Kurdistan, the finding cannot be generalized to other Kurdish language dialects. It is suggested that in future further studies like this study will be done in other Kurdish language dialects such as northern and southern Kurmanji and on a number of more subjects.

\section{Conclusion}

The information regarding the phonological inventory, consonant acquisition and percentage of consonants correct in Kurdish language can be helpful to assessment, diagnosis and intervention for Kurdish speaking children. The knowledge about norms and normal development is an important starting point for all clinical decisions, assessments and intervention. The results provide the opportunity to compare the scope and extent of speech difficulty in Kurdish speaking children.

\section{Ethical Considerations}

\section{Compliance with ethical guidelines}

The ethical considerations were approved by the University of Social Welfare and Rehabilitation Science's Ethics Committee.

\section{Funding}

This article is part of a master thesis of Shahla Fatemi Syadar approved in University of Social Welfare and Rehabilitation Sciences, Tehran, Iran.

\section{Conflict of interest}

The authors declare that there is no conflict of interest.

\section{Acknowledgements}

The authors of this study thank the children, who participated in this research, as well as the officials of the health centers and welfare and nurseries of Bukan City.

\section{References}

[1] Broomfield J, Dodd B. The nature of referred subtypes of primary speech disability. Child Language Teaching and Therapy. 2004; 20(2):135-51. [DOI:10.1191/0265659004ct267oa]

[2] McLeod S, Baker E, Murdoch BE, Goozée J, Whelan BM, Docking K. Current clinical practice for children with speech impairment. Paper presented at the $26^{\text {th }}$ World Congress of the International Association of Logopedics and Phoniatrics. 29 August- 2 September 2004, Brisbane, Australia.

[3] McLeod S, Harrison LJ. Epidemiology of speech and language impairment in a nationally representative sample of 4-to 5-year-old children. Journal of Speech, Language, and Hearing Research. 2009; 52(5):1213-29. [DOI:10.1044/10924388(2009/08-0085)]

[4] Jessup B, Ward E, Cahill L, Keating D. Prevalence of speech and/or language impairment in preparatory students in northern Tasmania. International Journal of Speech-Language Pathology. 2008;10(5):364-77. [DOI:10.1080/17549500701871171] [PMID]

[5] Law J, Boyle J, Harris F, Harkness A, Nye C. Prevalence and natural history of primary speech and language delay: findings from a systematic review of the literature. International Journal of Language and Communication Disorders. 2000; 35(2):165-88. [DOI:10.1080/136828200247133]

[6] Zarifian T, Modarresi Y, Tehrani LG, Kazemi MD, Salavati M. The Persian version of phonological test of diagnostic evaluation articulation and phonology for Persian speaking children and investigating its validity and reliability. Auditory and Vestibular Research. 2017; 23(4):10-20.

[7] Bishop DV, Adams C. A prospective study of the relationship between specific language impairment, phonological disorders and reading retardation. Journal of Child Psychology and Psychiatry. 1990; 31(7):1027-50. [DOI:10.1111/j.1469-7610.1990.tb00844.x] [PMID]

[8] Gangji N, Pascoe M, Smouse M. Swahili speech development: preliminary normative data from typically developing pre-school children in Tanzania. International Journal of Language \& Communication Disorders. 2015; 50(2):151-64. [DOI:10.1111/1460-6984.12118] [PMID]

[9] Nathan L, Stackhouse J, Goulandris N, Snowling MJ. The development of early literacy skills among children with speech difficulties: A test of the critical age hypothesis. Journal of Speech, Language, and Hearing Research. 2004; 47(2):377-91. [DOI:10.1044/1092-4388(2004/031)]

[10] Shriberg LD, Austin D, Lewis BA, McSweeny JL, Wilson DL. The Percentage of Consonants Correct (PCC) metric: Extensions and reliability data. Journal of Speech, Language, and Hearing Research. 1997; 40(4):708-22. [DOI:10.1044/jslhr.4004.708]

[11] Shriberg LD, Kwiatkowski J. Phonological disorders III: A procedure for assessing severity of involvement. Journal of Speech and Hearing Disorders. 1982; 47(3):256-70. [DOI:10.1044/jshd.4703.256] [PMID]

[12] Shriberg LD, Austin D, Lewis BA, McSweeny JL, Wilson DL. The Percentage of Consonants Correct (PCC) metric: Extensions and reliability data. Journal of Speech, Language, and Hearing Research. 1997; 40(4):708-22. [DOI:10.1044/jslhr.4004.708] 
[13] Bernthal JE, Bankson NW, Flipsen P. Articulation and phonological disorders: Speech sound disorders in children. New York: Pearson; 2009. [PMID]

[14] McLeod S. The international guide to speech acquisition. Clifton Park, New York: Thomson Delmar Learning; 2007.

[15] Amayreh MM, Dyson AT. The acquisition of Arabic consonants. Journal of Speech, Language, and Hearing Research. 1998; 41(3):642-53.[DOI:10.1044/jslhr.4103.642] [PMID]

[16] Yalçınkaya F, Bayar Muluk N, Budak B. Speech sounds acquisition evaluated by Speech Sound Development Test (SSDT) in Turkish-Speaking children. The Journal of International Advanced Otology. 2010; 6(1):60-6.

[17] Phoon HS, Abdullah AC, Lee LW, Murugaiah P. Consonant acquisition in the Malay language: A cross-sectional study of preschool aged Malay children. Clinical Linguistics \& Phonetics. 2014; 28(5):329-45. [DOI:10.3109/02699206.2013. 868517] [PMID]

[18] Gangii N. Phonological development in Swahili: A descriptive, cross-sectional study of typically developing pre-schoolers in Tanzania ( $\mathrm{PhD}$ dissertation). Cape Town: University of Cape Town; 2012. [PMCID]

[19] Zarifian T, Modaresi Y, Dastjerdi M, Salavati M. Percentage of correct consonants in Persian speaking children and its psychometric features. Journal of Exceptional Children. 2013; 13(4):46-53.

[20] Fox AV, Dodd B. Phonologically disordered GermanSpeaking Children. American Journal of Speech-Language Pathology. 2001; 10(3):291-307. [DOI:10.1044/10580360(2001/026)]

[21] Brice AE, Carson CK, Dennis O'Brien J. Spanish-English articulation and phonology of 4-and 5-year-old preschool children: An initial investigation. Communication Disorders Quarterly. 2009; 31(1):3-14. [DOI:10.1177/1525740108327447]

[22] Phoon HS. The phonological development of Malaysian English Speaking Chinese children: A normative study $(\mathrm{PhD}$ dissertation). New Zealand: University of Canterbury; 2010.

[23] MacLeod AA, Sutton A, Trudeau N, Thordardottir E. The acquisition of consonants in Québécois French: A cross-sectional study of pre-school aged children. International Journal of Speech-Language Pathology. 2011; 13(2):93-109. [DOI:10.31 09/17549507.2011.487543] [PMID]

[24] Hua Z, Dodd B. The phonological acquisition of Putonghua (modern standard Chinese). Journal of Child Language. 2000; 27(1):3-42. [DOI:10.1017/S030500099900402X] [PMID]

[25] Zarifian T, Tehrani LG, Modaresi Y, Kazemi M D, Salavati M. The Percentage of Vowel Correct Scale in Persian Speaking Children. Iranian Rehabilitation Journal. 2014; 12(1):5-8.

[26] Dodd B, Holm A, Hua Z, Crosbie S. Phonological development: a normative study of British English-speaking children. Clinical Linguistics \& Phonetics. 2003; 17(8):617-43. [DOI:10.1 080/0269920031000111348] [PMID]

[27] Minorsky V. Mongol place-names in Mukri Kurdistan. Bulletin of the School of Oriental and African Studies. 1957; 19(1):58-81. [DOI:10.1017/s0041977x00119202]

[28] Kreyenbroek PG. On the Kurdish language: The Kurds. Abingdon: Routledge; 2005.
[29] Asher RE, Simpson JM. The encyclopedia of language and linguistics. Oxford: Pergamon Press; 1993.

[30] Rahimpour M, Dovaise MS. A phonological contrastive analysis of Kurdish and English. International Journal of English Linguistics. 2011; 1(2):73. [DOI:10.5539/ijel.v1n2p73]

[31] Parhizi A. [The weight of Kurdish poetry and matching with Persian poetry weight (Persian)]. Tehran: Ketab-e zaman; 2008.

[32] Rokhzadi A. [Phonetics and grammar in Kurdish Language (Persian)]. Sanandj: Kurdistan Publication; 2011.

[33] Haig G, Matras Y. Kurdish linguistics: A brief overview. STUF - Language Typology and Universals. 2002; 55(1):3-14. [DOI:10.1524/stuf.2002.55.1.3]

[34] Zahedi MS, Alinezhad B, Rezai V. The sonority sequencing principle in Sanandaji/Erdelani Kurdish: An optimality theoretical perspective. International Journal of English Linguistics. 2012; 2(5):72. [DOI:10.5539/ijel.v2n5p72]

[35] Karimidustan GhH. [Syllable structure in Kurdish language (Persian)]. Journal of Faculty of Literature and Humanities of Mashhad. 2003; 35(1-2):235-48.

[36] Kalbasi I. [Mahabadi dialect of Kurdish (Persian)]. Tehran: Institute for Cultural Studies and Research; 1983.

[37] Haresabadi F, Ebadi A, Shirazi TS, Dastjerdi Kazemi M. Design and validation of a Photographic Expressive Persian Grammar Test for children aged 4-6 years. Child Language Teaching and Therapy. 2016; 32(2):193-204. [DOI:10.1177/0265659015595445]

[38] Lawshe CH. A quantitative approach to content validity. Personnel psychology. 1975; 28(4):563-75. [DOI:10.1111/j.1744-6570.1975.tb01393.x]

[39] Fatemi Syadar Sh. [The study of consonant acquisition in 3-5 years Kurdish-speaking children in Bukan (Persian)] (MSc. thesis). Tehran: University of Social Welfar and Rehabilitation Sciences; 2016.

[40] Ingram D. Phonological disability in children. Amsterdam: Elsevier Publishing Company; 1977.

[41] Grunwell P. Clinical Phonology. London: Croom Helm; 1987. [PMID] [PMCID]

[42] Shriberg LD, Tomblin JB, McSweeny JL. Prevalence of speech delay in 6-year-old children and comorbidity with language impairment. Journal of speech, language, and hearing research. 1999; 42(6):1461-81. [DOI:10.1044/jslhr.4206.1461] 